\title{
Evaluation of Antiaggressive Activity of Capparis zeylanica Root Extract in Experimental Animal Model
}

\author{
Sunil Kumar MISHRA ${ }^{*}$, Paras Nath SINGH', Satya Deo DUBEY² \\ ${ }^{1}$ Indian Institute of Technology (BHU), Varanasi 221 005, India; skmishra.phe@iitbhu.ac.in ("corresponding author) \\ ${ }^{2}$ Institute of Medical Science (BHU), Varanasi 221 005, India
}

\begin{abstract}
Aggression can ensue due to exposure to an intimidating situation. Aggression is prominently seen when a disturbance occurs in the fine balance of neurotransmitters such as 5-hydroxytryptamine, gamma-aminobutyric acid, dopamine and their receptor subtypes. The present study investigated the ability of 100,200 and $400 \mathrm{mg} / \mathrm{kg}$ of ethanolic extract of Capparis zeylanica root (EECZ) circumvent aggression. Foot shock induced aggression, isolation-induced aggression, resident-intruder aggression and water competition test were utilized as models for screening of antiaggressive activity. Extract was given orally at three different dose levels (100, $200 \mathrm{and} 400 \mathrm{mg} / \mathrm{kg})$ once daily for three consecutive days, while Diazepam $(2.5 \mathrm{mg} / \mathrm{kg})$, was administered as positive control. EECZ significantly $(p<0.05)$ minimized aggression dose dependently in the entire dose (100, 200, $400 \mathrm{mg} / \mathrm{kg}$ ). Results suggested that EECZ showed significant antiagressive activity in aforementioned validated models of aggression. EECZ at all dose levels (100, $200 \mathrm{and} 400 \mathrm{mg} / \mathrm{kg}) \mathrm{have}$ shown promising anti-aggressive activity qualitatively comparable to that of diazepam $(2.5 \mathrm{mg} / \mathrm{kg})$.
\end{abstract}

Keywords: aggression, antistress, Capparis zeylanica

\section{Introduction}

An exaggerated or fearful response to an appropriate or inappropriate condition may be observed during anxiety (Blanchardet et al., 2001). Increased anxiety provokes elevated aggression. Such exaggerated responses may induce subtle alterations of different integrated systems resulting in undesirable symptoms of emotional reactivity reflected as aggression. Aggression is an "overt behavior with the intension of inflicting physical damage on the opponent" (Moyer, 1968). Aggression generally ensues due to conflicting interests associated with restricted territory, electrical, sensory, chemical stimulation or with the removal of positive re-enforcements (Katherine, 2006). Although aggression is an adaptive response, if it is prolonged it can have serious repercussions on the health and social behavior of the individual. Numerous natural remedies have found acceptance as anxiolytic agents as they diffuse the unwarranted effects produced by synthetic agents. The selected medicinal plant for present study (Capparis zeylanica Linn., C. horrida Linn., Capparis brevispina DC.) is known as Indian caper belonging to family Capparidaceae. In Sanskrit it is known as Vyakhranakhi, kinkani, tapasapriya, granthila, karambha (Satyanarayana et al., 2008). It grows in moist habitat and is found throughout the majour parts of India. In different parts of India it is known with different names like Asadhua in Orissa, Kathotti in tamil etc. Almost all the parts ie. root, bark, fruits, leaves, fruits, seeds are used for different type of ailments. Capparis zeylanica
Linn. (Capparidaceae) is used as a (Rasayan) drug in the Ayurvedic system of medicines is reported to posses anti oxidant, antipyretic, analgesic, antimicrobial and immunostimulant activity (Ghule et al., 2006) as we know that "Rasayans" are minly recommended for immune disorder. The plants possess sedative property specially the root portion (Chopra et al., 1992). Root bark ten gram with one cup water crush and filter; this juice is narcotic, useful for relieving accidental pain and the leaf paste applies on piles and on breast pain (Das et al., 2011). The paste of the root is used by Mundas tribes of Ranchi district (Jharkhand) for body ache (Schults et al., 1984). The alcoholic extract of the root of plant has been reported to posses CNS depressant property and the significant effect is also reported in anti-convulsant effect (Varsha, 2011), antinociceptive (Mishra et al., 2011). It contains alkaloids, phytosterols, saponins, flavonoids, tannins, mucilaginous substances, saponins and fatty acid (Satyanarayana et al., 2008). The constituents like total phenolic compounds (43.625 \pm 1.45 $\mathrm{mg} / \mathrm{gm}$ of dry extract), total tannins $(24.75 \pm 1.23 \mathrm{mg} /$ gm of dry extract), total flavonols $(1.653 \pm 1.41 \mathrm{mg}$ rutin equivalents/g dry extract), total flavonoids (0.876 \pm 0.26 $\mathrm{mg} / \mathrm{gm}$ Rutin/g of dry extract), Saponins $(1.22 \pm 1.35 \mathrm{mg} /$ gm of dry extract) and fatty acids $(0.0867 \pm 0.01 \mathrm{mg} / \mathrm{gm}$ of dry extract) are reported to be present in the Capparis zeylanica root extract (Mishra et al., 2012). The same extract is being utilized for the present anti-depressant activity. 
128

\section{Material and methods}

\section{Plant material}

Capparis zeylanica Linn., C. horrida Linn., C. brevispinia DC. were collected in the month of March from Medicinal Plant garden of Banaras Hindu University, Varanasi. It was identified, confirmed and authenticated by comparison with an authentic specimen in herbarium. A voucher specimen (H. P. L. 512) of the plant including the root is deposited in the department of Pharmaceutics, Institute of Technology, Banaras Hindu University, Varanasi for future reference.

\section{Extraction}

Roots of Capparis zeylanica were separated from the plant, chopped, dried and powdered. The coarse dried root powder of Capparis zeylanica $(100 \mathrm{~g})$ was extracted with $250 \mathrm{ml}$ ethanol using the Soxhlet apparatus at temp. not exceeding $60^{\circ} \mathrm{C}$ for $72 \mathrm{hrs}$. The resulting mixture was filtered using muslin cloth followed by Whatman filter paper (No. 1). The aliquots obtained were dried on water bath at $50^{\circ} \mathrm{C}$ and stored at $-4^{\circ} \mathrm{C}$ until required for use. The yield obtained was $10.46 \% \mathrm{w} / \mathrm{w}$ of the dried Capparis zeylanica root.

\section{Animals}

Adult albino rats (250-400 g) and Wister mice (25-30 g) of either sex were obtained from the Animal House of the Institute and were randomly distributed into different experimental groups. The rats were housed in groups of six in polypropylene cages at an ambient temperature of $25 \pm 10^{\circ} \mathrm{C}$ and $45-55 \% \mathrm{RH}$ with a $12: 12 \mathrm{~h}$ light/dark cycle. Animals were provided with commercial food pellets and water ad libitum. All studies were performed in accordance with the guide for the care and use of laboratory animals.

\section{Drug treatment}

In the acute toxicity study no deaths were observed during the period at the doses tested up to $2000 \mathrm{mg} / \mathrm{kg}$. Hence, the EECZ was administered orally at three different dose levels (100, 200 and $400 \mathrm{mg} / \mathrm{kg}$ ) once daily for three consecutive days. Control group of animals received suspension of 1\% CMC in distilled water. Diazepam (2.5 $\mathrm{mg} / \mathrm{kg}$, i.p.) was used as standard drug and were administered intraperitoneally to rodents $30 \mathrm{~min}$. before experiments for comparison. Experiments were conducted on day 3 , one hour after the last drug administration.

\section{Safety evaluation}

EECZ was administered to 10 mice and 10 rats in a dose of $2 \mathrm{~g} / \mathrm{Kg}$ p.o and observations were made for gross behavioral changes such as locomotion, rearing, respiration, tremors, passivity, righting reflex, lacrimation and mortality for 14 days (Ghosh M.N., 1984).

\section{Assessment of anti aggressive activity}

The four most widely used rodent models were chosen to evaluate the effect of EECZ on aggressive behavior, viz.: foot shock-induced aggression, isolation-induced aggression, resident intruder aggression and water competition test.

\section{Foot shock-induced aggression}

Weight matched Swiss mice were divided into four groups (each containing 6 pairs), treated with vehicle, EECZ $(100,200$, and $400 \mathrm{mg} / \mathrm{kg} \mathrm{BW})$ or diazepam respectively, once daily for 14 consecutive days. On the $14^{\text {th }}$ day, $1 \mathrm{~h}$ after the last oral treatment, all pairs of mice were subjected to foot shock by placing them in an aggressometer (Techno) for $3 \mathrm{~min}$. During a $3 \mathrm{~min}$ observation period, every $5 \mathrm{sec}$ a $60-\mathrm{Hz}$ current was delivered for $5 \mathrm{sec}$. Each pair of mice was dosed and tested without previous exposure. The total numbers of fights were recorded for each pair (Vogel, 2002).

\section{Isolation-induced aggression}

Male Swiss mice (body weight of $25 \pm 5 \mathrm{~g}$ ) were kept isolated in small cages for two months. Prior to the drug treatment, the aggressive behavior of the isolated mouse was assessed against a male mouse (similar in weight to that of the isolated mouse, and accustomed to living in a group) and put into the cage of an isolated mouse for 5 min. Immediately, the isolated mouse started to attack the "intruder". The aggressive behavior of the isolated mouse was characterized by the tail hitting on the bottom of cage, biting and screaming. Isolated mice not showing aggressive behavior were excluded from the test. One day after the initial trial, isolated rodents were distributed into four groups $(n=6)$ and were treated with vehicle, EECZ (100, 200 , and $400 \mathrm{mg} / \mathrm{kg}$ ) or Diazepam (2.5 mg/kg i.p.) for 14 consecutive days. One hour after the last dose, aggressive behavior of the isolated mouse against a male mouse was evaluated for 5 min (Muehlenkamp et al., 1994). Aggressive behavior related parameters assessed during this test were latency to first attack, screaming, pursuit frequency, tail rattle, aggressive posture, and total number of fights.

\section{Water competition test}

Albino rats (Wistar strain, 250-400 g) were paired and housed in separate cage. After 6 days of acclimatization, animals were deprived of water for 23 hrs. At the end of this, pairs of water deprived animals were administered with the vehicle and 60 minutes later, a water bottle having a spout was introduced such that only one animal of a pair can drink at a time. Frequency and time in seconds of spout possession were recorded for 5 minutes and the aggressive animal of the pairs was marked for identification. Animals were then provided with water for 55 minutes after which the water bottle was withdrawn for 23 hours. The test was repeated on the second day. On second day instead of the control drug, the aggressive animals received 
Diazepam (2.5 mg/kg), $100 \mathrm{mg} / \mathrm{kg}, 200 \mathrm{mg} / \mathrm{kg}$ and 400 $\mathrm{mg} / \mathrm{kg}$ EECZ which was administered 60 minutes prior to the recording and aggressive bursts were observed for 5 minutes (Vogel, 2002).

\section{Resident-intruder aggression}

Male rats $(400 \pm 20 \mathrm{~g})$ were tested in their home cages for aggression against a smaller $(200 \pm 20 \mathrm{~g})$ male intruder. Before the start of the experiments, each resident male rat was kept in a pair with one female rat in a cage for 15 days, and were randomly divided into four groups $(\mathrm{n}=6)$. Drug treatment was started from the 16 th day and only male rats of each pair were administered with vehicle, EECZ (100, 200 , and $400 \mathrm{mg} / \mathrm{kg}$ ) or diazepam (2.5 mg/kg i.p.) for 14 consecutive days. The resident female was removed from the cage $30 \mathrm{~min}$ before the start of test. One hour after the last oral treatment, a male intruder $(\sim 200 \mathrm{~g})$ was placed in the territorial cage of the resident male, and behavior of the resident male was observed for the next $15 \mathrm{~min}$. During this period, the time until the first attack (in seconds), number of attacks, and duration of each attack (in seconds) were recorded by a blind observer (Siever, 2008).

\section{Statistical analysis}

Results are expressed as mean \pm SEM. Data for foot shock induced test was analyzed using unpaired student $t^{\prime}$ ' test. Data from the water competition test was analyzed using paired student ' $\mathrm{t}$ ' test. $p<0.05$ was considered as the level of significance.

\section{Results}

Foot shock-induced aggression

EECZ significantly reduced the total number of fight as compared to control in dose dependently manners (Fig. 1). Mean number of fights were dose dependently reduced

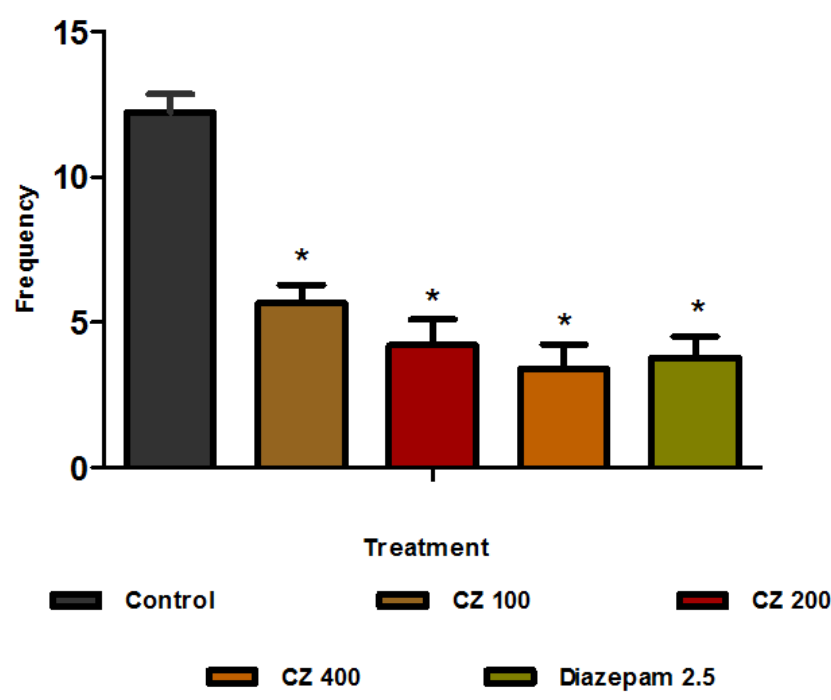

Fig. 1. Effect of EECZ on foot shock-induced aggressive behavior. Control $=6$ and treatment extract $n=6,{ }^{*} p<0.001$ compared to control in the EECZ treated groups. The effect of the higher dose of the EECZ ( $400 \mathrm{mg} / \mathrm{kg}$ ) tested was identical to that observed in the diazepam treated group.

\section{Isolation-induced aggression}

All the dose of EECZ $(100,200$, and $400 \mathrm{mg} / \mathrm{kg})$ significantly increased latency time to first attack (Fig. 2) while the number of aggressive postures, aggressive pursuit, tail traiting frequency and attacks were significantly reduced by all three doses of EECZ. These effects of EECZ (100, 200 , and $400 \mathrm{mg} / \mathrm{kg}$ ) were identical to that of diazepam $(2.5 \mathrm{mg} / \mathrm{kg})$ (Fig. 3).

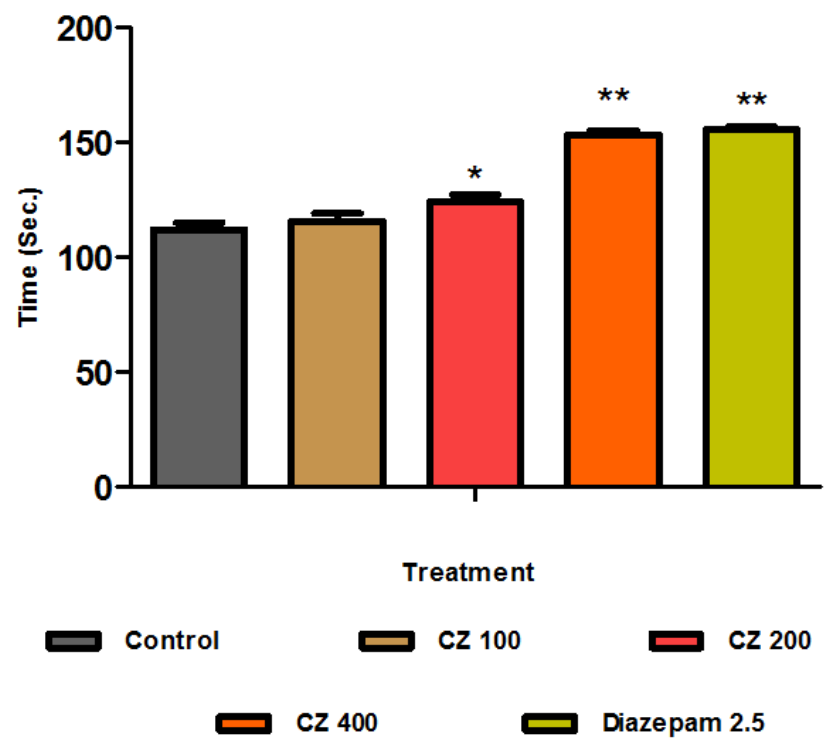

Fig. 2. Effect of EECZ on latency time to isolation-induced first attack. Control $=6$ and treatment extract $n=6,{ }^{*} p<.01$, ${ }^{* *} p<0.001$ compared to control

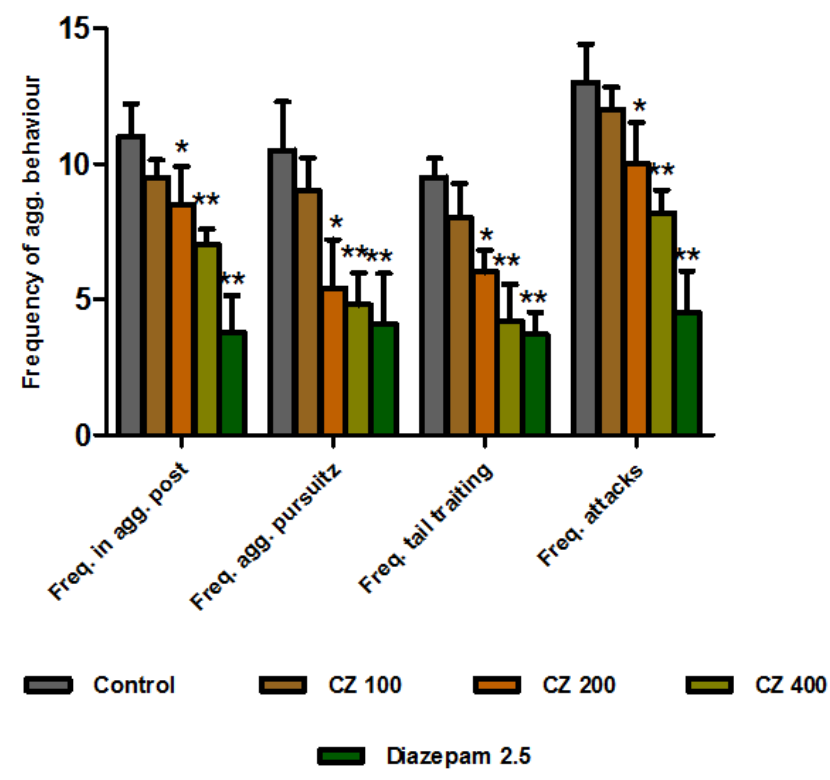

Fig. 3. Effect of EECZ on frequency of various isolation-induced aggressive behavior. Control $=6$ and treatment extract $n=6,{ }^{*} p<$ $0.05,{ }^{* *} p<0.001$ compared to control 
130

\section{Water competition test}

The average time of spout possession and frequency of spout possession in the water competition test are depicted in Fig. 4 and Fig. 5. EECZ at a dose of $200 \mathrm{mg} / \mathrm{kg}$ and 400 $\mathrm{mg} / \mathrm{kg}$ produced a significant reduction in spout gaining frequency along with a reduction in time spent which was found to be statistically significant $(p<0.05)$ compared to the control.

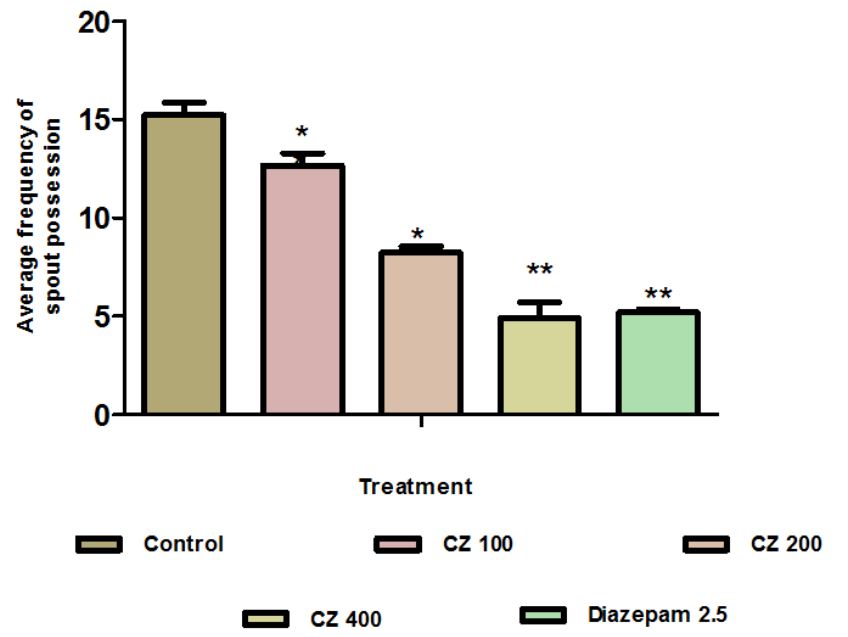

Fig. 4. Effect of EECZ on average frequency of spout possession. Control $=6$ and treatment extract $n=6,{ }^{*} p<.0 .001$ and ${ }^{*} p<0.005$ compared to control

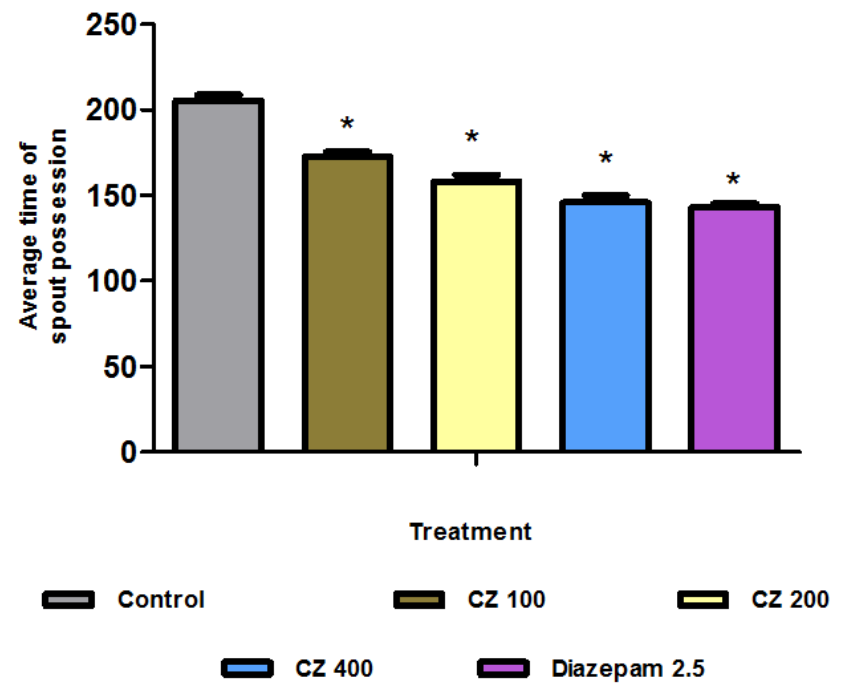

Fig. 5. Effect of EECZ on average time of the spout possession. Control $=6$ and treatment extract $n=6,{ }^{*} p<0.001$ as compared to control

\section{Resident-intruder aggression}

All the dose of EECZ (100. 200, and $400 \mathrm{mg} / \mathrm{kg}$ ) significantly prolonged the latency period of first attack (Fig. 6) and significantly reduced the frequency of aggressive posture, aggressive grooming and total number of attacks (Fig. 7). The total duration of fighting was also reduced significantly by all the doses $(100,200$ and $400 \mathrm{mg} / \mathrm{kg}$ ) of EECZ (Fig. 8). The observed effects of diazepam in this model were qualitatively similar to those of EECZ.

\section{Discussion}

The main of the described experiments was to verify whether effective anti-depressive, anxiolytic, and cognitive function modulating treatment regimen established for EECZ can also modify aggressive behaviour of rodents. Aggression and violence are significant public health problems (Hollander et al., 2003) that have received only limited attention of neurologists interested in identifying novel psychotherapeutics. Many neurological disorders (e.g. personality disorders, schizophrenia, bipolar disorder etc.) are characterized byimpulsive aggressive behaviour (Orengo et al., 2008), and aggressive behaviour is alsooften encountered in demented patients (Klaus et al., 2002). Analysis of aggression in different animal species could provide a firm

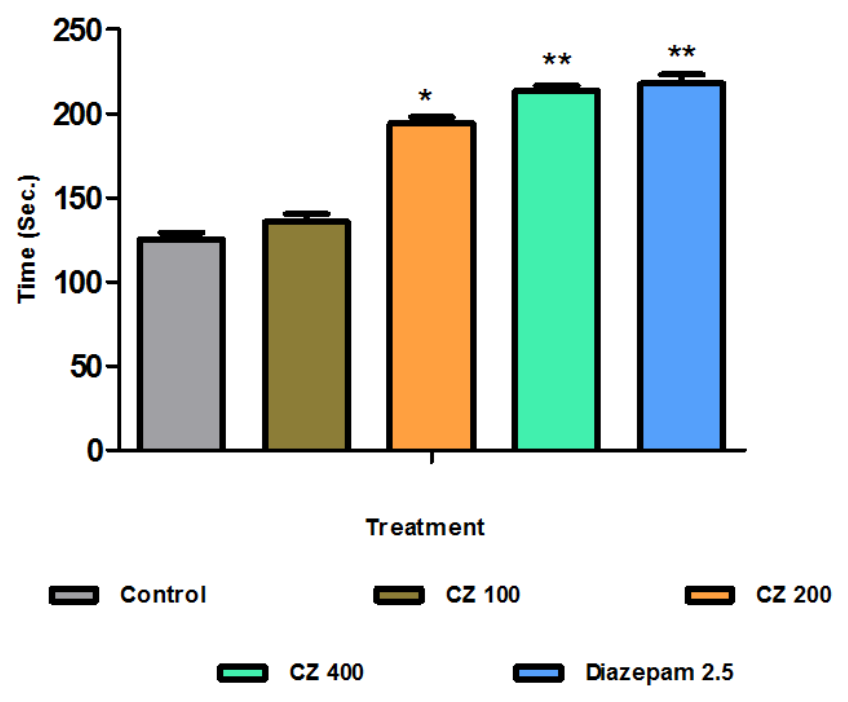

Fig. 6. Effect of EECZ on latency period of first attack against resident intruder. Control $=6$ and treatment extract $n=6,{ }^{*} p<0.05$, ${ }^{* *} p<0.001$ compared to control

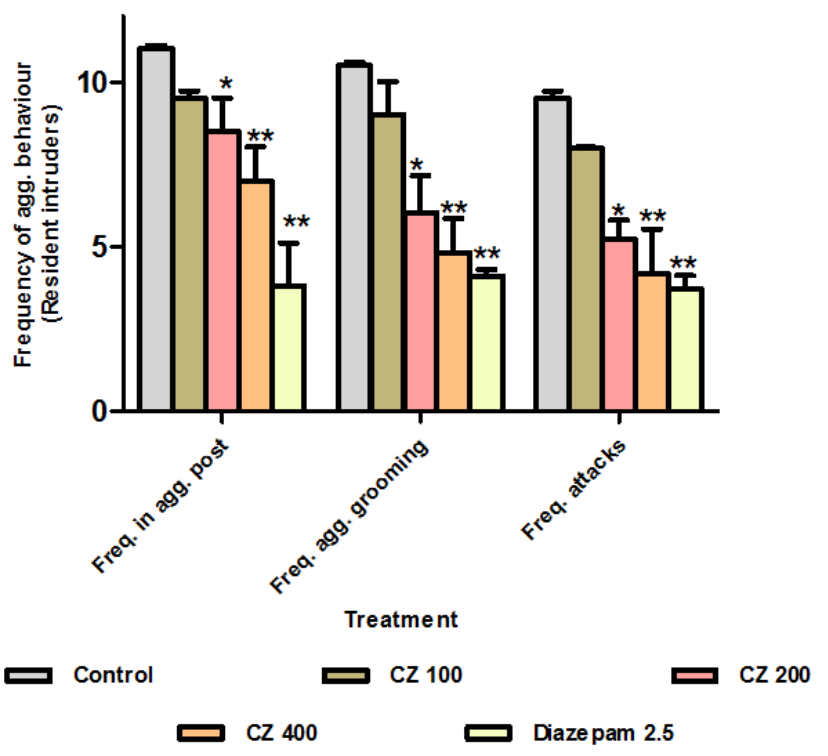

Fig. 7. Effect of EECZ on frequency of various resident intruder aggressive behaviors. Control $=6$ and treatment extract $\mathrm{n}=6,{ }^{*} p<0.01,{ }^{* *} p<0.001$ compared to control 


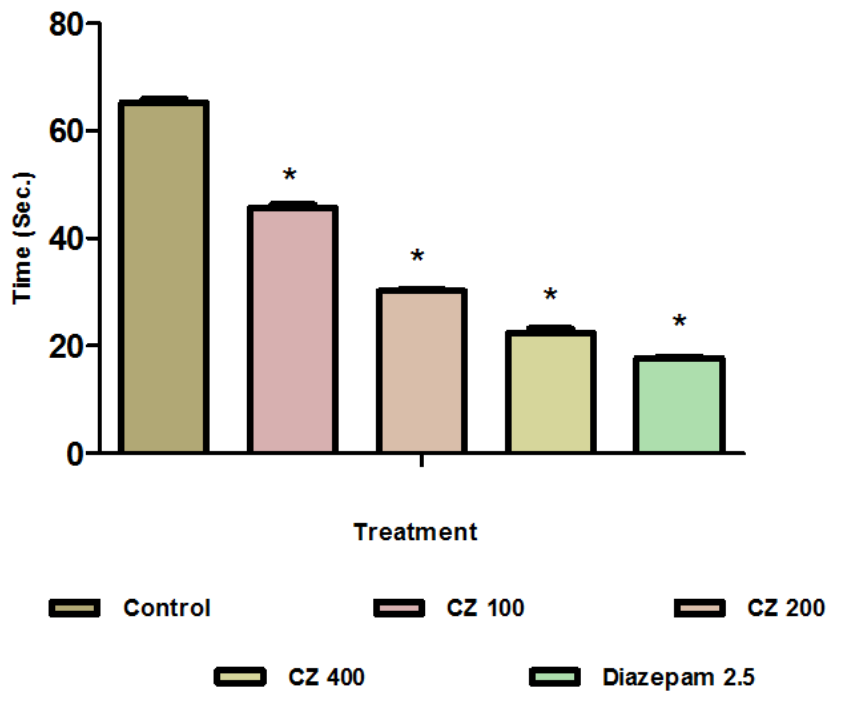

Fig. 8. Effect of EECZ on total duration of fighting against resident intruder. Control $=6$ and treatment extract $n=6,{ }^{*} p<0.001$ compared to control

understanding of human violence and the therapeutic measures to be taken to combat it (Adams, 1979). Exposure of an animal to a threatening situation elicits a behavioral repertoire referred to as aggression. The behavioral profile may be manifested in the form of offensive and defensive aggression (Blanchard et al., 1977). Offensive behavior is characterized by initiative of the aggressor and devastation to the opponent (Oliver et al., 1990). On the other hand defensive behavior lacks initiative and the animal does not impose intentional damage (Sijbesma et al., 1991). In animal aggression, the involvement of different neuronal circuits has been demonstrated. The initiation and execution of aggression is related to the disturbance in the fine balance of serotonin, dopamine, gamma amino butyric acid (GABA) and their particular receptor subtypes. Aggressive laboratory animals generally display decrease in brain 5-HT turnover (Mos et al., 1992). The term aggression is widely employed to indicate various patterns of psychological or sociological behavior resulting from pathological, biochemical or physiological alteration of central nervous system constituents. There are many psychiatric disorders such as schizophrenia and Alzheimer's disease which show close association with aggression (Bernard et al., 1975). Like any other behavior, aggression is also controlled and modulated by neurotransmitters. The agonist of 5-HT1A/5-HT1B and antagonist of 5-HT2A/5HT2C receptors have been reported to possess antiaggressive properties (Tizabi et al., 1989). Bernard et al. (1975) showed that dopamine levels and measurement of dopamine synthesis and turnover in the whole brain have increased in aggressive strains of mice and in mice that have just engaged in aggressive behavior. In the isolationinduced aggressive behavior model the level of dopamine increases in the striatum (Tsuda et al., 1988). It has been reported that expression of aggression is an alternative mechanism to decrease the nor-adrenaline increased due to stress (Rosana et al., 2005). The present anti-aggressive study was carried out to explore knowledge about the beneficial effect of EECZ in the parameters of aggression. The paradigm such as foot shock induced aggression and water competition test provide an assessment of the rodents level of defensive behavior, which in turn would reflect the extent of anxiousness or fear the animal experiences (Tanaka et al., 1988). In rats, defensive behavior is composed of a host of responses like vocalization, leaping, rearing, running and facing each other which depend on the nature of threat the animal envisages. In the water competition test, water deprivation induces high rank motivation resulting in competition for a common goal which is "water". Therefore it serves to demonstrate that the animal with greater dominance or aggression will take hold of the spout faster and for a longer duration. If the drug administered minimizes this urge it would indicate the anxiolytic property of the drug. The placidity in behavior induced in animals by EECZ may be due to its ability to alter the level of neurotransmitters and $\mathrm{Na}+/ \mathrm{K}+$-ATPase. The enzyme $\mathrm{Na}+$ / $\mathrm{K}+$-adenosine triphosphatase $(\mathrm{Na}+\mathrm{K}+$-ATPase) has an accomplished role in regulating brain function, such as repolarization of the neuronal membranes and neurotransmitters uptake/release. Individual variations in the activity of brain $\mathrm{Na}+/ \mathrm{K}+$ ATPase may result in differences in the functioning of the brain, which, in turn, could produce behavioral divergences (Mos et al., 1992). Stimulation of the $\mathrm{Ca}+2$ receptor could induce the release of 5- hydroxytryptamine (Bernard et al., 1975). The enhanced turnover of 5-HT can cause blunting of aggression and could be a plausible reason for the antiaggressive property of EECZ. In this regard the effect of EECZ on serotonin levels is of particular interest. Antidepressants, anxiolytics, cognitive function modulators, anticonvulsants, and other psychoactive agents are now identified as potential anti-aggressive therapeutics because of their neurotransmitter modulator properties. EECZ has been investigated in various experimental models of depression, anxiety and memory and learning to reveal its modulator action on a variety of neurotransmitters.

\section{Conclusions}

In conclusion, the EECZ in all doses was found to be efficacious in producing serenity and masking the constellation of behavioral changes encountered during aggressive bouts making it a promising naturally derived product.

\section{References}

Adams DB (1979). Brain mechanisms for offense, defenseand submission. Behav Brain Sci 2:201-224.

Bernard BK, Finkelstein ER, Everett GM (1975). Alterations in mouse aggressive behavior and brain monoamine dynamics as a function of age. Physiol Behav 15:731-736.

Blanchard DC, Griebel G, Blanchard RJ (2001). Mouse defen- 
132

sive behaviors: pharmacological and behavioral assays for anxiety and panic. Neurosci Biobehav Rev 25:205-218.

Blanchard RJ, Blanchard DC, Takahashi T (1977). Attack and defensive behavior in the albino rat. Anim Behav 25:622634.

Chopra RN, Nayer SL, Chopra IC (1992). Glossary of Indian medicinal plants. CSIR, New Delhi, 50-52 p.

Das C, Dash S, Sahoo DC, Sahu AK, Hota R, Rout D (2011). Wound healing activity of Capparis zeylanica (root). J Chem Pharm Res 3(5):15-19.

Ghosh MN (1984). Fundamentals of experimental pharmacology, $2^{\text {nd }}$ ed., Scientific Book Agency, Calcutta, $156 \mathrm{p}$.

Ghule BV, Murugananthan G, Nakhat PD, Yeole PG (2006). Immunostimulant effect of Capparis zeylanica Linn. leaves. J Ethnopharmacology 108(2):311-315.

Hollander E, Tracy KA, Swann AC (2003). Divalproex in the treatment of impulsive aggression: efficacy in cluster B personality disorders. Neuropsychopharmacology 28:11861197.

Katherine $S$ (2006). The role of testosterone in aggression. M J M 6:32-40.

Klaus A, Miczek E, Fish W, Joseph de Bold F, Rosa de Almeida MM (2002). Social and neural determinants of aggressive behavior: pharmacotherapeutic targets at serotonin, dopamine and gaminobutyric acid systems. Psychopharmacology 163:434-458.

Mishra SK, Singh PN (2011). Ethnomedicinal, phytochemical and pharmacological review of Capparis zeylanica Linn. Res J Pharma, Biol Chemical Sci 2(2):506.

Mishra SK, Singh PN, Dubey SD (2011). Evaluation of antioxidant activities in methanolic extract of Capparis zeylanica Linn. root. Revista Lat Amer De Qui (In press).

Mos J, Olivier B, Poth M, Van Aken H (1992). The effects of intraventricular administration of eltoprazine, 1-(3-trifluoromethylphenyl) piperazinehydrochloride and 8-hydroxy2-(di-n-propylamino) tetralin on resident intruder aggression in the rat. Eur J Pharmacol 212:295-298.

Moyer KE (1968). Kinds of aggression and their physiological basis. Common Behav Biol 2A:65-87.

Muehlenkamp F, Luciont A, Vogel WH (1995). Effects of selective serotonergic agonists on aggressive behavior in rats. Pharmacol Biochem Behav 50:671-674.
Oliver B, Van Dalem D, Hartog J (1990). A new class of psychoactive drug serenics. Drugs Future 11:473-499.

Orengo CA, Khan J, Kunik ME (2008). Aggression in Individuals newly diagnosed with dementia. Am J Alzheimers Dis Other Demen 23:227-232.

Rosana A, José G, Barbosa de C, Marco ACB (2005). Brain Research 1058:178-182.

Satyanarayana T, Anjana AM, Vijetha P (2008). Phytochemical and pharmacological review of some Indian Capparis species. Pharmacol Rev 2:36-45.

Schults RG, Hofmann A (1984). Psychoactive plants in need of chemical and pharmacological study. Proc Indian Acad Sci (Plant Sci) 93(3):281-284.

Siever LJ (2008). Neurobiology of aggression and violence. Am J Psychiatry 165:429-442.

Sijbesma H, Schipper J, de Kloet ER, Mos J, VanAken H, Olivier B (1991). Postsynaptic 5-HT1 receptors and offensive aggression in rats: A combined behavioral and autoradiographic study with eltoprazine. Pharmacol Biochem Behav 38:447-458.

Tanaka T, Yoshida M, Yokoo H, Tomita M, Tanaka M (1998). Expression of aggression attenuates both stress-induced gastric ulcer formation and increases in noradrenalin release in the rat amygdala assessed by intracerebral microdialysis. Pharmacol Biochem Behav 59:27-31.

Tizabi Y, Thoa NB, Maengwyn-Davies GD, Kopin IJ, Jacobowitz DM (1979). Behavioral correlation of catecholamine concentration and turnover in discrete brain areas of three strains of mice. Brain Res 166:199-205.

Tsuda A, Tanaka M, Ida Y, Shirao I, Gondoh Y, Oguchi M, Yoshida M (1988). Expression of aggression attenuates stress induced increases in rat brain noradrenaline turnover. Brain Res 474:174-180.

Varsha SR (2011). Ethnopharmacognostical studies of Capparis zeylanica (Linn.): A potential psychoactive plant. Journal of Pharmacy Research 4(3):910-911.

Vogel HG (Ed.) (2002). Drug Discovery and Evaluation: Pharmacological Assays, $2^{\text {nd }}$ ed., Springer-Verlag, Heidelberg, Germany, 425-430 p. 